\title{
Knowledge-Gap among Doctors in the Niger Delta Region of Nigeria about Sexual and Reproductive Health
}

\author{
Emmanuel Columba Inyang-Etoh ${ }^{1}$, Anyiekere Morgan Ekanem², Anietimfon Sunday Akpan ${ }^{3}$ \\ ${ }^{1}$ Department of Obstetrics and Gynaecology, University of Uyo, Uyo, Nigeria \\ ${ }^{2}$ Department of Community Health, University of Uyo, Uyo, Nigeria \\ ${ }^{3}$ Department of Obstetrics and Gynaecology, University of Uyo Teaching Hospital, Uyo, Nigeria \\ Email: emmacol2000@yahoo.com
}

Received 6 December 2015; accepted 19 December 2015; published 24 December 2015

Copyright (C) 2015 by authors and OALib.

This work is licensed under the Creative Commons Attribution International License (CC BY). http://creativecommons.org/licenses/by/4.0/

(c) (i) Open Access

\begin{abstract}
Objective: Sexual and reproductive health the way it is currently conceptualized is a new discipline in medicine, and many medical doctors whose responsibility is to provide information and service to promote this essential component of health do not fully understand the concept. This study was designed to determine the level of knowledge of Nigerian doctors about sexual and reproductive health. Methods: Partly pre-coded questionnaires were administered to a cross section study of doctors for self-completion to test their knowledge about sexual and reproductive health. Results: One hundred and ninety-eight doctors with a mean age of 33.7 years old and a mean duration of practice of 6.9 years were surveyed. Nearly all $(99.5 \%)$ of the respondents had heard of the term sexual and reproductive health, but only $15.7 \%$ of the respondents were able to define sexual and reproductive health correctly. Doctors who were working in health facilities situated in educational institutions were more significantly able to define sexual and reproductive health correctly than others $(p=0.001)$. Major sources of information on sexual and reproductive health to respondents were journals, colleagues, lectures and conferences. Most (96.5\%) respondents knew that sexual and reproductive health was related to the United Nation's MDGs but $30.2 \%$ did not know that it equally related to MDGs 4 and 6 . There was no significant association between occupational profile of respondents and their level of knowledge about sexual and reproductive health ( $p$ > 0.05). Conclusion: There was a knowledge-gap among the doctors in the Niger Delta region of Nigeria about sexual and reproductive health as $20.2 \%$ of them demonstrated low level of knowledge about sexual and reproductive and only $15.7 \%$ of them could define the concept correctly.
\end{abstract}

\section{Keywords}

Sexual, Reproductive Health, Knowledge, Medical Doctors, Nigeria
Subject Areas: Gynecology \& Obstetrics, Public Health, Women's Health

How to cite this paper: Inyang-Etoh, E.C., Ekanem, A.M. and Akpan, A.S. (2015) Knowledge-Gap among Doctors in the Niger Delta Region of Nigeria about Sexual and Reproductive Health. Open Access Library Journal, 2: e2151.

http://dx.doi.org/10.4236/oalib.1102151 


\section{Introduction}

Sexual and reproductive health is defined as a state of complete physical, mental and social well being and not merely the absence of disease or infirmity in matters related to the reproductive system and to its functions and processes [1]. This comprehensive and holistic concept of sexual and reproductive health was borrowed from the WHO concept of sexual health developed in 1975 and adopted at the International Conference on Population and Development (ICPD), which held in Cairo in 1994. This new concept is a paradigm shift from the hitherto narrow concept of maternal/child care and family planning [1] [2].

The current concept of sexual and reproductive health has been expanded to include maternal and child health, adolescent health, prevention and control of sexually transmitted infections (STIs) including human immunodeficiency virus infection/acquired immunodeficiency syndrome (HIV/AIDS), fertility regulation, prevention and management of infertility, prevention and management of genital tract malignancies, sexual and reproductive rights of women, reproductive health of men and elimination of harmful traditional practices [3]-[5].

Adopting a life cycle approach, sexual and reproductive health and the rights therein begin from the womb and end in the tomb. A female's sexual and reproductive right is violated if a couple prefers a male child to a female; if boys are treated preferentially by parents; if the girl child is subjected to female genital mutilation; if the girl child is married out before sexual maturity; if the adolescent girl lacks information and education about her sexuality; if she lacks access to maternity services during pregnancy and childbirth and if she cannot regulate her fertility and access treatment for infertility. Her right is also violated if she is subjected to inhuman treatment and socioeconomic deprivation by her husband or by the in-laws if her husband dies, and if she lacks access to treatment of conditions associated with menopause as well as prevention and management of genital tract malignancies [4].

Information from the Nigerian Federal Office of Statistics 2014 reveals that the level of sexual and reproductive health attained by Nigerians is abysmal [5]. Maternal mortality ratio is still over 500 per 100,000 live births, utilization of family planning methods is still a mere $15 \%$, attainment of adolescent health is poor and harmful traditional practices are still prevalent in some communities in the country [6] [7].

The millennium developmental goals (MDG) 3, 4, 5, and 6 namely, attainment of gender equity, reduction of infant mortality, promotion of maternal health and prevention/control of infectious diseases respectively are directly related to the attainment of sexual and reproductive health, and primary care doctors like general practitioners, family physicians, community physicians and obstetricians and gynaecologists as well as oncologists are crucial to the provision of information and services to promote sexual and reproductive health [8] [9]. Doctors also have a comparative advantage over other health workers in advocacy and influence of policy formulation to promote sexual and reproductive health in the society, including legislation to abolish harmful traditional practices [10].

Interestingly, sexual and reproductive health was only expanded and accorded priority globally barely two decades ago, and the Nigerian National Reproductive Health Policy and Strategy was constituted in 2001, while the subject only entered the country's medical curriculum in 2005 [3] [4]. This development has invariably created knowledge-gap, as a doctor who graduated from medical school before the year 2000 may not have heard the phrase sexual and reproductive health, let alone understand this rather composite and holistic concept.

This study was designed to assess the level of knowledge of doctors in the Niger Region of Nigeria about sexual and reproductive health. Findings from this study will probably help stake holders make a case for the introduction of sexual and reproductive health into the curriculum of the Continuing Medical Education programme of the Medical and Dental Council of Nigeria (MDCN). It is the responsibility of the MDCN to promote quality medical education at undergraduate and postgraduate levels, as well as continuing medical education and continuing professional development of all doctors practicing medicine in Nigeria.

\section{Methods}

\subsection{Study Design and Study Area}

This was across sectional questionnaire-based exploratory study among medical doctors who were attending an Annual General Meeting and Scientific Conference of the Nigerian Medical Association (NMA), Akwa Ibom State branch, Nigeria in August 2014.

Akwa Ibom State is located in the Niger Delta region of Nigeria with a population of 3.9 million people ac- 
cording to the Nigerian census conducted in 2006 and projected to 4.8 million people by 2014 [6] [11]. Akwa Ibom state is one of the 36 states of the federal republic of Nigeria, and it has one federal teaching hospital, 3 academic institutional medical centres, 16 general hospitals and 125 private clinics [12]. There were 205 medical officers and 14 medical specialists practicing in state-owned health facilities at the time of the study, while a few of the doctors were engaged in administrative duties in the ministry of health. The teaching hospital had 60 house officers, 190 resident doctors and 65 medical specialists practicing in the hospital according to the human resource unit of the hospital.

\subsection{Data Collection and Analysis}

Approval was obtained from the Akwa Ibom State Ministry of Health Research Ethical Committee before commencement of the study. Permission was also obtained from the leadership of the Association before the questionnaires were administered. Participants were counseled on the purpose of the study and informed that participation in the study was voluntary. The questionnaires which were structured and partly pre-coded had been pretested among a cross section of 20 doctors attending an Ordinary General Meeting (OGM) 3 months earlier and necessary corrections made.

The questionnaires were administered by trained research assistants to a cross section of doctors at the Annual Conference for self-completion. Respondents were instructed to complete the questionnaires independently and submit as soon as completed to the research assistants. The questions were set to obtain the occupational profile of the respondents, the ability of respondents to define sexual and reproductive health correctly, the people they thought sexual and reproductive health concerned and what category of doctors they thought were directly involved in the promotion of sexual and reproductive health, as well as the relationship between sexual and reproductive health and the United Nation's Millennium Developmental Goals (MDG). For example, respondents were asked two open ended questions namely, what do you think sexual and reproductive health refer to? And Do you think sexual and reproductive health is essential for the attainment of total human health? If yes, why? The closed ended questions included: Which of the following persons do you think are concerned with sexual and reproductive health? Women only, Men only, Both Women and Men, Children, Others, please specify. Do you think sexual and reproductive health is related to the UN's Millennium Developmental Goals? Which of the Millennium Developmental Goals are related to sexual and reproductive health? Eradication of Poverty/hunger, Basic education, Gender equity, Infant survival, Maternal health, Infectious disease control, Environmental sustainability, Global partnership. Which of these categories of doctors do you think are directly involved in the promotion of sexual and reproductive health, Gynaecologists, General surgeons, Community physicians, General practitioners, Paediatricians, Oncologists, Orthopaedic surgeons? The respondents were expected to select Yes, No or I don't know option for each question.

A total of 11 questions were intended to test respondents' knowledge about sexual and reproductive health. Each item was assigned a score of 1 for a correct response and 0 for a wrong response. A score of 0 - 5 was graded as low, 6 - 8 as moderate and 9 - 11 as high level of knowledge about sexual and reproductive health.

Data generated from the study were coded and entered into the soft ware of the Statistical Package for Social Sciences (SPSS), Version 17 Inc. Chicago, Illinois, USA. Descriptive statistics was performed for continuous variables, while the association between categorical variables was compared using the Chi square test. A confidence interval of 95\% was adopted and differences were considered significant at a p-value of less than 0.05 .

\section{Results}

One hundred and ninety eight medical doctors participated in the study. The mean age of respondents was 33.07 \pm 7.70 years old, and the mean duration of their practice was 6.9 years with a standard deviation of 7.59 years. Nearly all (99.5\%) the respondents had heard of the term sexual and reproductive health and $99.0 \%$ of them expressed their desire to learn more about the concept. Only $15.7 \%$ of the respondents were able to define sexual and reproductive health correctly, definitions stated by $58.6 \%$ of the respondents were incorrect, while $25.7 \%$ of them declined to respond. The majority (79.8\%) of the respondents had moderate to high level of knowledge about the concept.

Table 1 shows that a vast majority (86.4\%) of the respondents had basic MB, BS degree, and $75.8 \%$ of them had practiced for less than 10 years as at the time of the study. The majority $(70.2 \%)$ of them were working with the University of Uyo Teaching Hospital, with 33.8\% of them being house officers. Figure 1 shows that common 
Table 1. Occupational profile of respondents in the study population.

\begin{tabular}{|c|c|c|}
\hline Characteristics & Frequency & Percentage (\%) \\
\hline \multicolumn{3}{|l|}{ Qualification } \\
\hline Basic MB, BS & 171 & 86.4 \\
\hline ЧPG Diploma & 10 & 5.1 \\
\hline MSc. & 4 & 2.0 \\
\hline $\mathrm{PhD}$. & 5 & 2.5 \\
\hline Professional fellowship & 8 & 4.0 \\
\hline \multicolumn{3}{|l|}{ Practice duration } \\
\hline$<10$ years & 150 & 75.8 \\
\hline$>10$ years & 48 & 24.2 \\
\hline \multicolumn{3}{|l|}{ Work place } \\
\hline General hospital & 32 & 16.2 \\
\hline ®Medical centre & 9 & 4.5 \\
\hline Ministry of health & 9 & 4.5 \\
\hline Teaching hospital & 139 & 70.2 \\
\hline Private clinic & 9 & 4.5 \\
\hline \multicolumn{3}{|l|}{ Designation } \\
\hline House officers & 67 & 33.8 \\
\hline Medical officers & 49 & 24.7 \\
\hline Sr. Medical officers & 35 & 17.7 \\
\hline Resident doctors & 40 & 20.2 \\
\hline Consultants & 7 & 3.5 \\
\hline Total & 198 & $100.0 \%$ \\
\hline
\end{tabular}

${ }^{\circledR T}$ These are health facilities situated in academic institutions like polytechnics and universities; YPG stands for post graduate.

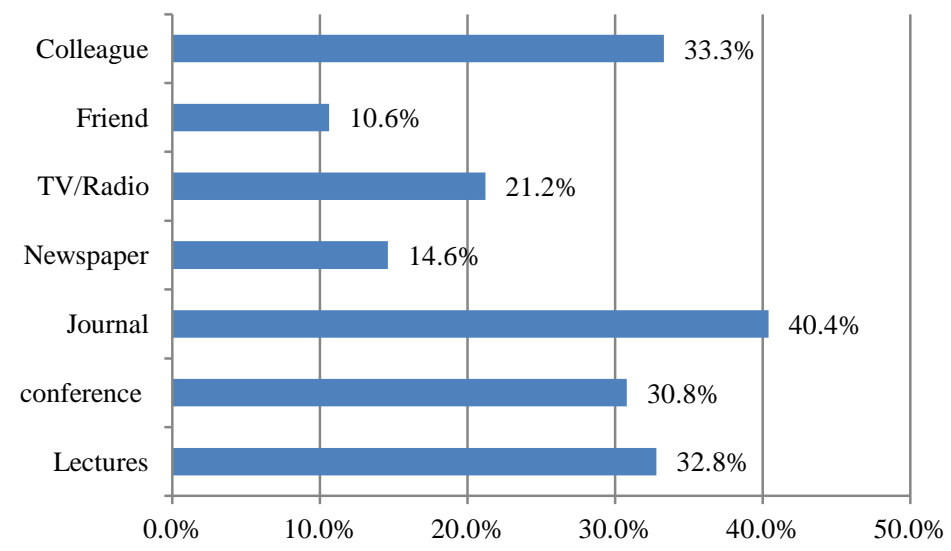

Figure 1. Sources of information about sexual and reproductive health. 
sources of information about sexual and reproductive health to the respondents in descending order of frequency were journal, colleagues, lectures and conferences. Respondents were less likely to hear about sexual and reproductive health from their friends.

Most of the respondents correctly posited that sexual and reproductive health was related to the United Nation's Millenium Developmental Goals (96.5\%); that gynaecologists were involved (93.4\%); and that it was essential for the attainment of complete human health (99.0\%) as shown in Table 2. An abysmal proportion of respondents knew that it also related to MDG 4 (30.2\%), MDG 6 (23.4\%) and that oncologists were equally involved (36.4\%).

Table 3 shows the association between occupational profile of respondents and their ability to define sexual and reproductive health correctly. Respondents working in medical centres situated in educational institutions

Table 2. Respondents' knowledge about sexual and reproductive health (positive responses only).

\begin{tabular}{lcc}
\hline \multicolumn{1}{c}{ Knowledge of Reproductive Health } & Frequency & Percentage \\
\hline Reproductive health concerns both men and women & 138 & 69.7 \\
Reproductive health is related to MDGs & 191 & 96.5 \\
Reproductive health relates to MDG 3 & 80 & 41.7 \\
Reproductive health relates to MDG 4 & 58 & 30.2 \\
Reproductive health relates to MDG 5 & 157 & 80.6 \\
Reproductive health relates to MDG 6 & 45 & 23.4 \\
Gynaecologists are involved in reproductive health & 185 & 93.4 \\
Community physicians are involved in reproductive health & 168 & 84.8 \\
General practitioners are involved in reproductive health & 144 & 72.7 \\
Oncologist are involved in reproductive health & 72 & 36.4 \\
Reproductive health, essential for the attainment of complete human health & 196 & 99.0 \\
\hline
\end{tabular}

Table 3. Association between respondents' occupational profile and ability to define sexual and reproductive health correctly.

\begin{tabular}{|c|c|c|c|c|}
\hline \multirow{2}{*}{ Factors } & \multicolumn{2}{|c|}{ Definition of Reproductive Health } & \multirow{2}{*}{ Total } & \multirow{2}{*}{ Statistical Tests and Values } \\
\hline & Correct & Incorrect & & \\
\hline \multicolumn{5}{|l|}{ Practice duration } \\
\hline$<10$ yrs & $24(16.0)$ & $126(84.0)$ & $150(100.0)$ & \multirow{2}{*}{$\begin{array}{c}\mathrm{X}^{2}=0.055 \\
\mathrm{df}=1 \\
\mathrm{P}=0.814\end{array}$} \\
\hline$\geq 10$ years & 7 (14.6) & $41(85.4)$ & $48(100.0)$ & \\
\hline \multicolumn{5}{|l|}{ Place of Work } \\
\hline General Hospital & $0(0.0)$ & $32(100.0)$ & $32(100.0)$ & \multirow{5}{*}{$\begin{array}{c}\mathrm{X}^{2}=14.378 \\
\mathrm{df}=4 \\
\mathrm{p}=0.001\end{array}$} \\
\hline Medical centre & $4(44.4)$ & $5(55.6)$ & $9(100.0)$ & \\
\hline Min. of Health & $1(11.1)$ & $8(88.9)$ & $9(100.0)$ & \\
\hline Teaching Hospital & $26(18.7)$ & $113(81.3)$ & $139(100.0)$ & \\
\hline Private clinic & $0(0.0)$ & $9(100.0)$ & $9(100.0)$ & \\
\hline \multicolumn{5}{|l|}{ Designation } \\
\hline House officers & $13(19.4)$ & $54(80.6)$ & $67(100.0)$ & \multirow{5}{*}{$\begin{array}{c}X^{2}=12.94 \\
d f=4 \\
p=0.012\end{array}$} \\
\hline MOs & $4(8.2)$ & 45 (91.8) & $49(100.0)$ & \\
\hline Snr MOs & $2(5.7)$ & $33(94.3)$ & $35(100.0)$ & \\
\hline Resident doctors & $12(30.0)$ & $28(70.0)$ & $40(100.0)$ & \\
\hline Consultants & $0(0.0)$ & $7(100.0)$ & $7(100.0)$ & \\
\hline
\end{tabular}

MOs refers to medical officers; Snr MOs refers to senior medical officers. 
(44.4\%) and the teaching hospital (18.7\%) were significantly able to define sexual and reproductive health correctly when compared to respondents working in other health facilities $(p=0.001)$. Respondents who were resident doctors significantly defined sexual and reproductive health correctly when compared to other categories of respondents $(\mathrm{p}=0.012)$.

The association between occupational profile of respondents and their knowledge of the concept of sexual and reproductive health is shown in Table 4. There was no statistically significant association between occupational profile of respondents and their level of knowledge about the concept of sexual and reproductive health $(\mathrm{p}>0.05)$.

\section{Discussion}

Unless medical doctors themselves understand the composite and complex concept of sexual and reproductive health, they will not be able to contribute their quota to the promotion of this essential component of health to the populace. The study population was made up of medical doctors in their prime, with a mean age of 33.07 years old and mean duration of practice of 6.9 years. This finding is a reflection of the setting of this study in which a cross section of Nigerian doctors attending an annual general meeting and scientific conference had their knowledge about the subject surveyed. Anecdotal evidence has shown that such meetings are often largely attended by the young doctors in our environment.

Table 4. Association between occuaptional profile of respondents and knowledge of the concept of sexual and reproductive health.

\begin{tabular}{|c|c|c|c|c|}
\hline \multirow{2}{*}{ Factors } & \multicolumn{2}{|c|}{ Knowledge of Sexual and Reproductive Health } & \multirow{2}{*}{ Total } & \multirow{2}{*}{ Statistical Tests and Values } \\
\hline & Poor & Good & & \\
\hline \multicolumn{5}{|l|}{ Qualification } \\
\hline Basic MB, BS & $36(21.1)$ & 135 (78.9) & $171(100.0)$ & \multirow{5}{*}{$\begin{array}{c}X^{2}=5.106 \\
d f=4 \\
p=0.154\end{array}$} \\
\hline 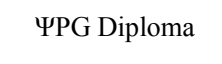 & $0(0.0)$ & $10(100.0)$ & $10(100.0)$ & \\
\hline MSc. & $2(50.0)$ & $2(50.0)$ & $4(100.0)$ & \\
\hline Ph.D & $1(20.0)$ & $4(80.0)$ & $5(100.0)$ & \\
\hline Fellowship & $1(12.5)$ & $7(87.5)$ & $8(100.0)$ & \\
\hline \multicolumn{5}{|l|}{ Practice Duration } \\
\hline$<10$ years & $32(21.3)$ & $118(78.7)$ & $150(100.0)$ & \multirow{2}{*}{$\begin{array}{c}\mathrm{X}^{2}=0.491 \\
\mathrm{df}=1 \\
\mathrm{p}=0.317\end{array}$} \\
\hline$\geq 10$ years & $8(16.7)$ & $40(83.3)$ & $48(100.0)$ & \\
\hline \multicolumn{5}{|l|}{ Workplace } \\
\hline General Hospital & $9(28.1)$ & $23(71.9)$ & $32(100.0)$ & \multirow{5}{*}{$\begin{array}{c}\mathrm{X}^{2}=3.116 \\
\mathrm{df}=4 \\
\mathrm{p}=0.561\end{array}$} \\
\hline${ }^{\circledR M}$ Medical Centre & $3(33.3)$ & $6(66.7)$ & $9(100.0)$ & \\
\hline Min. of Health & $2(22.2)$ & $7(77.8)$ & $9(100.0)$ & \\
\hline Teaching Hospital & $25(18.0)$ & $114(82.0)$ & 139 (100.0) & \\
\hline Private Clinic & $1(11.1)$ & 8 (88.9) & $9(100.0)$ & \\
\hline \multicolumn{5}{|l|}{ Designation } \\
\hline House Officers & 12 (17.9) & $55(82.1)$ & $67(100.0)$ & \multirow{5}{*}{$\begin{array}{c}\mathrm{X}^{2}=8.020 \\
\mathrm{df}=4 \\
\mathrm{P}=0.091\end{array}$} \\
\hline MOs & $16(32.7)$ & 33 (67.3) & $49(100.0)$ & \\
\hline Snr. MOs & $6(17.1)$ & 29 (82.9) & $35(100.0)$ & \\
\hline Residents Drs & $4(10.0)$ & $36(90.0)$ & $40(100.0)$ & \\
\hline Consultants & $2(28.6)$ & $5(71.4)$ & $7(100.0)$ & \\
\hline
\end{tabular}

MOs refers to medical officers; Snr MOs refers to senior medical officers. ${ }^{\circledR}$ These refer to health facilities situated in academic institutions like polytechnics and universities; $\Psi$ PG refers to post graduate. 
Nearly all (99.5\%) the respondents had heard of the term sexual and reproductive health, but they equally expressed their desire to learn more about the concept. This result is in agreement with findings from similar studies where most health-care providers have heard of new subjects and concepts in medicine but often lack in depth knowledge as was demonstrated in a study of knowledge and attitude of health-care providers towards the provision of emergency contraception in Lagos, Nigeria [13]. Such casual knowledge by doctors is attributed to lack of education in specific disciplines, and such a development has been shown to lead to negative attitude towards the provision relevant health information and services to the populace [14] [15].

The fact that only $15.7 \%$ of respondents were able to define sexual and reproductive health correctly has confirmed the need for formal education of practicing doctors in our environment in order to equip them for the task of providing relevant information and services to promote sexual and reproductive health [9] [16]. Major sources of information about sexual and reproductive health were journals, colleagues, lectures and conferences, whereas respondents were less likely to obtain such information from friends, similar to findings from a survey of adolescents' knowledge about reproductive health in Ile-Ife, Nigeria and Arusha, Tanzania, where respondents' friends were less likely sources of health related information [17] [18].

Even though most of the respondents knew that sexual and reproductive health was related to the United Nation's Millennium Developmental Goals (MDGs) 3 and 5, and that gynaecologists were involved, only an abysmal proportion knew that it also was related to MDGs 4 and 6, and that oncologists were equally involved in the promotion of sexual and reproductive health. This is a demonstration of the knowledge-gap, which could be filled through continuing medical education of doctors [9] [16] [19].

Interestingly, respondents who worked in health facilities situated in educational institutions were more able to define sexual and reproductive health correctly for reasons which have not been adduced by this study; notwithstanding, reading journals, attending lectures and conferences and interaction with colleagues, which were major sources of information for respondents in this study, could have been more prevalent among doctors in this group.

Although the majority (79.8\%) of the respondents are adjudged by the study to have moderate to high level of knowledge about sexual and reproductive health, they still need to learn more from any formal education programme targeted at equipping them with the needed knowledge and skills to provide information and services to promote sexual and reproductive health to the populace. The finding that the occupational profile of respondents did not significantly affect their level of knowledge has learnt credence to the need for doctors of all ages and designations to be educated on sexual and reproductive health.

In conclusion, there was a knowledge-gap among doctors practicing in the Niger delta region of Nigeria about sexual and reproductive health as $20.2 \%$ of them demonstrated low level of knowledge about the concept and only $15.7 \%$ of them were able to define sexual and reproductive health correctly. Such deficit in knowledge undermines the ability of these practicing doctors to provide needed information and services to promote sexual and reproductive to the populace. The need for the Medical and Dental Council of Nigeria (MDCN) to draw up a curriculum for the continuing medical education of practicing doctors in Nigeria on sexual and reproductive health has become imperative.

\section{Acknowledgements}

We wish to express our appreciation to the doctors who served as research assistants by administering the questionnaires to the respondents.

\section{References}

[1] Population Information Network (POPIN) (1995) Report of the International Conference on Population and Development. Cairo, 5-13 September 1994. United Nations (UN), New York.

[2] Giami, A. (2012) Sexual Health: The Emergence, Development and Diversity of a Concept. Annual Review of Sex Research, 1, 1-35.

[3] FMOH (2001) National Reproductive Health Policy and Strategy to Achieve Quality Reproductive and Sexual Health for All Nigerians. Federal Ministry of Health, Abuja.

[4] Adinma, J.I.B. (2003) Human Rights Code of Ethics on Women’s Sexual and Reproductive Healthcare for Health Professionals in Nigeria. FIGO/SOGON, Nnwei.

[5] Omo-Aghoja, L. (2013) Sexual and Reproductive Health: Concepts and Current Status among Nigerians. African 
Journal of Medical and Health Sciences, 2, 103-113.

[6] National Population Commission (NPC) Nigeria (2014) National Demographic and Health Survey (NDHS). National Population Commission, Abuja.

[7] FMOH. Sexual and Reproductive Development of Adolescents and Young People in Nigeria, 2007-2011. Federal Ministry of Health, Abuja, 31-34.

[8] United Nations' Millenium Developmental Goals (2014) Fact Sheet No. 290 Progress Report of the United Nations. Fact Sheet Updated May 2014.

[9] Olatunbosun, O. and Haslegrave, M. (2003) Incorporating Sexual and Reproductive Health Care in the Medical Curriculum in Developing Countries. Reproductive Health Matters, 21, 49-58.

[10] Coleman, E. (2002) Promoting Sexual Health and Responsible Sexual Behavior: An Introduction. Journal of Sex Research, 39, 1-6. http://dx.doi.org/10.1080/00224490209552111

[11] National Population Commission (NPC) (2006) Population of Akwa Ibom State. Final Report of the Nigerian Census.

[12] Akwa Ibom State Ministry of Health (AKSMOH) (2014) Number of Health Facilities and Health Personnel in the State. Updated Statistics of the Akwa Ibom State Ministry of Health for the Year 2014.

[13] Olufunke, M.E., Osaretin, A.T.E. and Inem, V. (2006) Health Care Providers’ Knowledge of, Attitudes towards and Provision of Emergency Contraceptives in Lagos, Nigeria. International Family Planning Perspectives, 32, 89-93. http://dx.doi.org/10.1363/3208906

[14] Njoku, O.A. and Ngome, E. (2012) Healthcare Providers' Perception of the Sexual and Reproductive Health Needs (Including Family Planning) of Elderly Women from Selected Sites in Botswana. World Journal of AIDS, 2, 143-158. http://dx.doi.org/10.4236/wja.2012.23020

[15] Tilahun, M., Mengistie, B., Egate, G. and Reda, A.A. (2012) Health Workers’ Attitude toward Sexual and Reproductive Health Services for Unmarried Adolescents in Ethiopia. Reproductive Health, 9, 19. http://dx.doi.org/10.1186/1742-4755-9-19

[16] Menwissen, L.E., Gorte, A.C., Kester, A.D.M. and Knottnerus, J.A. (2006) Can a Comprehensive Voucher Programme Prompt Changes in Doctors' Knowledge, Attitude and Practices Related to Sexual and Reproductive Health Care for Adolescents? A Case Study from Latin America. Tropical Medicine and International Health Journal, 6, 889-898. http://dx.doi.org/10.1111/j.1365-3156.2006.01632.x

[17] Omobuwa, O., Asekun-Olarinmoye, E.O. and Olajide, F.O. (2012) Knowledge and Perception of Reproductive Health Services among In-School Adolescents in Ile-Ife, Osun State, Nigeria. Journal of Medicine and Medical Sciences, 7, 481-488.

[18] Masatu, M.C., Ale, G.K. and Klepp, K. (2003) Frequency and Perceived Credibility of Reported Sources of Reproductive Health Information among Primary School Adolescents in Arusha, Tanzania. Scandinavian Journal of Public Health, 3, 216-223. http://dx.doi.org/10.1080/14034940210164894

[19] Tsimtsion, Z., Hatzimouratidis, K., Nakopoulon, E., Kyrana, E., Salpigidis, G. and Hatzichristou, D. (2006) Predictions of Physicians' Involvement in Addressing Sexual Health Issues. Journal of Sexual Medicine, 4, 583-588. http://dx.doi.org/10.1111/j.1743-6109.2006.00271.x

\section{Abbreviations Used in the Paper}

OGM: Ordinary General Meeting;

NMA: Nigerian Medical Association;

MDCN: Medical and Dental Council of Nigeria;

MDG: Millennium Developmental Goals;

WHO: World Health Organization;

UN: United Nations;

ICPD: International Conference on Population and Development;

STIs: Sexually Transmitted Infections;

HIV/AIDS: Human Immunodeficiency virus infection/Acquired Immunodeficiency Syndrome. 